\title{
A SUPOSTA ALTERAÇÃO DOS FUNDAMENTOS DO DIREITO ADMINISTRATIVO PELA NOVA REDAÇÃO DA LEI DE INTRODUÇÃO ÀS \\ NORMAS DO DIREITO BRASILEIRO (LINDB)
}

\section{THE SUPPOSED CHANGE TO THE FUNDAMENTALS OF ADMINISTRATIVE LAW BY THE NEW REDACTION OF INTRODUCTION TO THE RULES OF BRAZILIAN LAW ACT (LINDB)}

Mateus Bertoncini ${ }^{1}$

Doutor em Direito do Estado pela Universidade Federal do Paraná(2004). Professor do Corpo Permanente do Programa de Mestrado e Doutorado em Direito Empresarial e Cidadania do Centro Universitário Curitiba - UNICURITIBA. Professor Titular de Direito Administrativo da Faculdade de Direito de Curitiba - UNICURITIBA. Professor de Direito Administrativo da Fundação Escola do Ministério Público do Paraná - FEMPAR.

Resumo: O estudo que ora se propõe pretende responder, a partir do método indutivo, ao seguinte questionamento: haveria a LINDB alterado os fundamentos do regime jurídicoadministrativo? Para a solução do problema o artigo analisará o diagnóstico justificador do Projeto de Lei do Senado 349/2015, os princípios que o inspiraram (segurança jurídica e eficiência) e o próprio produto legislativo - os novos artigos (20 a 30) da Lei de Introdução às Normas do Direito Brasileiro -, para concluir a respeito da eventual mudança estrutural do Direito Administrativo nacional.

\footnotetext{
${ }^{1}$ Doutor em Direito do Estado pela Universidade Federal do Paraná (2004). Estágio Pós-Doutoral em Democracia e Direitos Humanos organizado pelo Ius gentium Conimbrigae/Centro de Direitos Humanos (IGC) sediado na Faculdade de Direito na Universidade de Coimbra (2020). Estágio Pós-Doutoral junto ao PPGD da Universidade Federal de Santa Catarina - UFSC (2014). Professor do Corpo Permanente do Programa de Mestrado e Doutorado em Direito Empresarial e Cidadania do Centro Universitário Curitiba - UNICURITIBA. Professor Titular de Direito Administrativo da Faculdade de Direito de Curitiba - UNICURITIBA. Professor de Direito Administrativo da Fundação Escola do Ministério Público do Paraná - FEMPAR. Procurador de Justiça do Ministério Público do Estado do Paraná. Endereço profissional: Rua Chile, 1.678, PPGD/UNICURITIBA, Bairro Rebouças, Curitiba, PR, CEP: 80.220181. E-mail: mateus.bertoncini@unicuritiba.edu.br Orcid: https://orcid.org/0000-0001-9687-5124 Lattes:http://lattes.cnpq.br/8390682026043566.
} 
Palavras-chave: Lei de Introdução às Normas do Direito Brasileiro; princípio da segurança jurídica; princípio da eficiência; Direito Administrativo; alteração do regime jurídicoadministrativo

\begin{abstract}
The research, by using the inductive method, aims to answer the following question: had LINDB changed the foundations of the legal-administrative regime? To solve the problem, the article analyzes the Senate Bill Project $n^{\circ} 349 / 2015$, the principles that inspired it (legal certainty and efficiency) and the legislative product itself - the new articles (20 to 30) of the Introduction to the Rules of Brazilian Law Act - to conclude about the possible structural change in the brazilian Administrative Law.
\end{abstract}

Keywords: Introduction to the Rules of Brazilian Law Act; legal certainty; efficency; Administrative Law; change to the foundations of the legal-administrative regime

\title{
Introdução
}

Por intermédio da Lei 13.655/2018 foram introduzidas diversas mudanças na Lei de Introdução às Normas do Direito Brasileiro (LINDB), que recebeu 10 (dez) novos artigos com a pretensão de alterar o Direito Público nacional, especialmente o Direito Administrativo, sob a alegação de que o Estado brasileiro, representado pelos órgãos de controle, é um "inimigo", instabilizando relações jurídicas em prejuízo da segurança e da eficiência, princípios fundamentais do Projeto de Lei do Senado 349/2015, gênese da referida Lei que alterou a LINDB.

Conforme as justificativas do projeto, as mudanças foram necessárias para se atualizar a Lei de Introdução, especialmente em relação à interpretação do Direito Público, porque a Lei de 1942 foi criada para orientar a interpretação do Código Civil de 1916, e, portanto, demandava mudanças após mais de 70 anos de vigência para também cuidar das numerosas alterações havidas no Direito brasileiro, especialmente no Direito Público.

No entanto, o diagnóstico justificador da criação legislativa - "o Estado inimigo", os princípios fundamentais inspiradores da Lei 13.655/2018 e alguns de seus artigos induzem o intérprete a pensar que as alterações da LINDB mudaram os próprios fundamentos do Direito 
Administrativo brasileiro, para prestigiar irredutivelmente a eficiência e a segurança dos negócios firmados entre o Estado-Administração e os particulares.

A importância do tema é evidente, sendo imprescindível que os estudiosos do Direito brasileiro, especialmente aqueles que se dedicam ao estudo do Direito Administrativo, se debrucem sobre cada um dos novos dispositivos da LINDB, criados pela Lei 13.655/2018, para verificar o efetivo teor dessas mudanças, o impacto delas no regime jurídico-administrativo e a pertinência sistêmica delas, inclusive no que diz respeito ao Direito Constitucional Administrativo (MORAES, 2002).

O estudo que ora se propõe pretende demonstrar, a partir do método indutivo, que o diagnóstico justificador do Projeto de Lei do Senado, os princípios que o inspiraram (segurança jurídica e eficiência) e o próprio produto legislativo - serão analisados alguns dos novos artigos da LINDB - podem levar à conclusão

de que teria havido uma profunda mudança nas bases do Direito Administrativo brasileiro. Em síntese, a pergunta central da pesquisa é a seguinte: haveria a LINDB, realmente, alterado o regime jurídico-administrativo?

\section{1. "Estado inimigo" - crítica ao diagnóstico que inspirou o legislador}

No livro em formato digital patrocinado pelo Senado Federal, que apresentou os "Estudos sobre o Projeto de Lei do Senado 349/2015, que inclui[u], na Lei de Introdução às Normas do Direito Brasileiro, disposições para aumentar a segurança jurídica e a eficiência na aplicação do direito público", afirma-se que o Estado no Brasil tem como marca registrada celebrar relações jurídicas com particulares, pessoas físicas ou jurídicas, caracterizadas pela desconfiança, pela ausência de parceria com o segundo e terceiro setores, produzindo um ambiente institucional negativo. Diz o Senador Antonio Anastasia (2015, p. 05), subscritor do projeto, que o "Estado será um inimigo", não numa perspectiva de futuro, como a frase isolada induz a pensar, mas no sentido de um comportamento presente, hodierno e contínuo que 
necessita ser interrompido e substituído por um novo comportamento estatal gerador de confiança, parceria e estabilidade (BERTONCINI, 2019, posição² 2927).

Esse "Estado inimigo", adversário dos administrados, das empresas e das entidades da sociedade civil, assim se expressa pelos seus órgãos de controle, interno e externo, colocando em "risco os ganhos de estabilidade institucional". Esse, pois, parece ter sido o mote inspirador da reforma da Lei de Introdução às Normas do Direito Brasileiro. É o que também se extrai da leitura da apresentação da mencionada obra digital e da justificativa ao Projeto de Lei do Senado 349/2015, anexado ao aludido livro.

Como fruto da consolidação da democracia e da crescente institucionalização do Poder Público, o Brasil desenvolveu, com o passar dos anos, ampla legislação administrativa que regula o funcionamento, a atuação dos mais diversos órgãos do Estado, bem como viabiliza o controle externo e interno do seu desempenho. Ocorre que, quanto mais se avança na produção dessa legislação, mais se retrocede em termos de segurança jurídica. $\mathrm{O}$ aumento de regras sobre processos e controle da administração tem provocado aumento da incerteza e da imprevisibilidade e esse efeito deletério pode colocar em risco os ganhos de estabilidade institucional (ANASTASIA, 2015, p. 49).

Esse diagnóstico induz ao entendimento de que no Brasil segurança jurídica e controle são conceitos antagônicos. Mais do que isso, o Estado é um inimigo que abusivamente exerce sua atividade de controle. Esse retrato parcial do Estado parece ter informado a elaboração da Lei 13.655/2018, que alterou a LINDB. (BERTONCINI, 2019, posição 2938). O "Estado inimigo", segundo se infere dos estudos que informaram a Lei 13.655/2018, necessitava ser reformado na sua forma de decidir, para se tornar um parceiro inspirador de confiança nas suas relações com os particulares, de modo a produzir estabilidade institucional.

A ideia central consistiu em se alterar a Lei de Introdução às Normas do Direito Brasileiro, para se "elevar os níveis de segurança jurídica e eficiência na criação e aplicação do direito público", por intermédio de medidas destinadas a "neutralizar importantes fatores de distorções da atividade jurídico-decisória pública" (ANASTASIA, 2015, p. 50). Os fatores apontados na justificativa do Projeto de Lei do Senado 349/2015 seriam os seguintes:

o alto grau de indeterminação de grande parte das normas públicas; a relativa incerteza, inerente ao Direito, quanto ao verdadeiro conteúdo de cada norma; a tendência à superficialidade na formação do juízo sobre complexas questões jurídico-públicas; a dificuldade de o Poder Público obter cumprimento voluntário e rápido de obrigação por terceiros, contribuindo para a inefetividade das políticas públicas; a instabilidade dos atos jurídicos públicos, pelo risco potencial de invalidação posterior, nas várias instâncias de controle; os efeitos negativos indiretos da exigência de que as decisões e controles venham

\footnotetext{
${ }^{2}$ Trata-se de e-book cuja referência denomina-se posição e não página. Nota-se, igualmente, que a numeração da posição no livro eletrônico é diferente da numeração de páginas de um livro impresso, posto que não se dá sequencialmente.
} 
de processos que demoram, custam e podem postergar cumprimento de obrigações; e o modo autoritário como, na quase totalidade dos casos, são concebidas e editadas normas pela Administração Pública (ANASTASIA, 2015, p. 50).

Para a equação desses problemas, "as diretrizes propostas pelos ilustres professores Carlos Ari Sundfeld e Floriano Marques Neto podem ser assim resumidas":

consagram alguns novos princípios gerais a serem observados pelas autoridades nas decisões baseadas em normas indeterminadas (arts. 20 e 21); conferem aos particulares o direito à transição adequada quando da criação de novas situações jurídicas passivas (art. 22); estabelecem o regime jurídico para negociação entre autoridades públicas e particulares (art. 23); criam a ação civil pública declaratória de validade, com efeito erga omnes, para dar estabilidade a atos, contratos, ajustes, processos e normas administrativas (art. 24); impedem a invalidação de atos em geral por mudança de orientação (art. 25); disciplinam os efeitos da invalidação de atos em geral, para torná-los mais justos (art. 26); impedem a responsabilização injusta de autoridade em caso de revisão de suas decisões (art. 27); impõem a consulta pública obrigatória para a edição de regulamentos administrativos (art. 28); e determinam a compensação, dentro dos processos, de benefícios ou prejuízos injustos gerados para os envolvidos (art. 29) (ANASTASIA, 2015, p. 50-51).

Grande parte das mudanças propostas no Projeto de Lei do Senado 349/2015 foram acolhidas pelo Congresso Nacional e sancionadas pelo Presidente da República, tornando-se a Lei 13.655/2018, que introduziu 10 (dez) novos artigos (20 a 30) na Lei de Introdução às Normas do Direito Brasileiro. Apenas um artigo, o 25, foi totalmente vetado, tendo havido alguns vetos parciais ${ }^{3}$ (BERTONCINI, 2019, posição 2938-2994).

\section{O alegado conflito entre segurança jurídica e controle}

Diversamente do afirmado na justificativa do Projeto de Lei do Senado 349/2015, o princípio da segurança jurídica não contrasta com os controles interno e externo da Administração Pública, basicamente controles de legalidade, legalidade sobre a qual se assenta a própria ideia de Estado de Direito (CANOTILHO, 1993, p. 371), verdadeira conquista civilizatória, exatamente para se substituir às monarquias absolutistas baseadas no arbitrário poder real, fonte permanente de insegurança e de ausência de direitos fundamentais, experiência igualmente vivenciada nos Estados totalitários, nas chamadas "ditaduras modernas" (BOBBIO, 2017, p. 211-213).

\footnotetext{
${ }^{3}$ Houve veto parcial ao parágrafo único do art. 23; ao inciso II do $\S 1^{\circ} \mathrm{e} \S 2^{\circ}$ do art. 26; aos $\S \S 1^{\circ}, 2^{\circ}$ e $3^{\circ}$ do art. 28; e ao $\S 2^{\circ}$ do art. 29.
} 
Com efeito, o Estado Democrático de Direito no Brasil contemporâneo é definido e estruturado pela Constituição de 1988, tendo como fundamentos, consoante o seu artigo $1^{\circ}$ : I a soberania; II - a cidadania; III - a dignidade da pessoa humana; IV - os valores sociais do trabalho e da livre iniciativa; e V - o pluralismo político. No artigo $3^{\circ}$, foram estabelecidos os fundamentos da República Federativa do Brasil: I - independência nacional; II - prevalência dos direitos humanos; III - autodeterminação dos povos; IV - não-intervenção; V - igualdade entre os Estados; VI - defesa da paz; VII - solução pacífica dos conflitos; VIII - repúdio ao terrorismo e ao racismo; IX - cooperação entre os povos para o progresso da humanidade; e X - concessão de asilo político (BERTONCINI, 2019, posição 3005).

Esse mesmo Estado constitucional contém um título específico, bastante extenso, como jamais houve na história das Constituições brasileiras, apenas para definir os Direitos e Garantias Fundamentais de qualquer brasileiro ou estrangeiro residente no País, título esse dividido em diversos capítulos destinados à definição dos "Direitos e Deveres Individuais e Coletivos", dos "Direitos Sociais", da "Nacionalidade", dos "Direitos Políticos", e dos "Partidos Políticos". Em outros termos, liberdade, igualdade e fraternidade estão garantidas constitucionalmente, fórmula que "exprimiu em três princípios cardeais todo o conteúdo possível dos direitos fundamentais" (BONAVIDES, 2017, p. 576-577).

A organização do Estado encontra definição no Título III, possuindo sete capítulos, definindo os seguintes temas: Da Organização Político Administrativa (1), da União (2), dos Estados Federados (3), dos Municípios (4), do Distrito Federal e dos Territórios (5), da Intervenção (6), e da Administração Pública (7).

No que se refere a esse último capítulo, chama a atenção o seu artigo 37, caput, que define os princípios que regem a Administração Pública no Brasil: "A administração pública direta e indireta de qualquer dos Poderes da União, dos Estados, do Distrito Federal e dos Municípios obedecerá aos princípios de legalidade, impessoalidade, moralidade, publicidade e eficiência", fundamental conjunto que não esgota o rol de princípios que informam a Administração Pública (BERTONCINI, 2002, p. 262-265).

No que tange ao exercício pelo Estado de sua função de controle, a Constituição de 1988, em seu artigo 31, define o controle interno e externo no âmbito municipal; o artigo 70, por sua vez, estabelece: “A fiscalização contábil, financeira, orçamentária, operacional e 
patrimonial da União e das entidades da administração direta e indireta, quanto à legalidade, legitimidade, economicidade, aplicação das subvenções e renúncia de receitas, será exercida pelo Congresso Nacional, mediante controle externo, e pelo sistema de controle interno de cada Poder".

O artigo 74 impõe aos Poderes Legislativo, Executivo e Judiciário a manutenção, de forma integrada de sistema de controle interno, com a finalidade de: "I - avaliar o cumprimento das metas previstas no plano plurianual, a execução dos programas de governo e dos orçamentos da União; II - comprovar a legalidade e avaliar os resultados, quanto à eficácia e eficiência, da gestão orçamentária, financeira e patrimonial nos órgãos e entidades da administração federal, bem como da aplicação de recursos públicos por entidades de direito privado; III - exercer o controle das operações de crédito, avais e garantias, bem como dos direitos e haveres da União; IV - apoiar o controle externo no exercício de sua missão institucional". No $\S 1^{\circ}$ do artigo, definiu-se que: “Os responsáveis pelo controle interno, ao tomarem conhecimento de qualquer irregularidade ou ilegalidade, dela darão ciência ao Tribunal de Contas da União, sob pena de responsabilidade solidária”. Por sua vez, o $§ 2^{\circ}$ prevê o controle popular da Administração Pública: “Qualquer cidadão, partido político, associação ou sindicato é parte legítima para, na forma da lei, denunciar irregularidades ou ilegalidades perante o Tribunal de Contas da União".

Em relação ao Ministério Público, não se deve olvidar que incumbe à Instituição, segundo o artigo 127 da CF, a "defesa da ordem jurídica, do regime democrático e dos interesses sociais e individuais indisponíveis", desempenhando a função de Ombudsman no sistema jurídico brasileiro (MARTINS JUNIOR, 2002, p. 86).

Quanto ao Poder Judiciário, basta lembrar a sua função de guardião da Constituição e das leis, para, em arremate, dizer ser inaceitável a pretensão de se defender a existência de conflito entre segurança jurídica e controle, de se querer apresentar os órgãos do sistema constitucional de controle da legalidade como inimigos da sociedade civil.

Em outros termos, a motivação do projeto contém em si uma contradição ao atribuir à legalidade e ao controle de legalidade efeito próprio do arbítrio e da ausência de controle, características imanentes às monarquias absolutistas, aos Estados totalitários. Trata-se de fundamentação marcadamente sofista, e, portanto, logicamente inconsistente. Esse é o primeiro 
defeito metodológico do Projeto de Lei do Senado 349/2015, o que naturalmente se transferiu para o próprio produto legislativo (BERTONCINI, 2019, posição 2994-3041).

\section{Estado legal versus Estado real}

O funcionamento do Estado no Brasil não é um primor; está longe do ideal no seu dia a dia nos planos federal, estadual, distrital e municipal. No entanto, daí para se afirmar que o Estado brasileiro é um "inimigo, jamais um parceiro", há uma distância muito grande. Confundir o Estado definido na Constituição de 1988, brevemente referido no item anterior, com o Estado real, em processo de paulatina construção, é, no mínimo, inadequado, constituindo-se esse equívoco no segundo problema metodológico do Projeto de Lei do Senado 349/2015, que se converteu na Lei 13.655/2018.

Está-se a falar de duas coisas inconfundíveis: o sistema normativo e o ambiente em que ele incide, sem se olvidar da interação entre essas esferas. O que não se pode, entretanto, é se confundir essas duas realidades como se ambas fossem a mesma coisa. Trata-se de mais um erro de diagnóstico, de mais um sofisma da justificativa do projeto, bastante parcial ao apresentar um cenário que compara coisas distintas: o direito posto e a realidade de sua aplicação, segundo a visão particular dos mentores do anteprojeto:

A existência desses fatores de distorção é conhecida pelos envolvidos, em função da experiência prática,
e este texto não tem condições de desenvolver um estudo detalhado a seu respeito. Avaliar em
profundidade como e quanto esses fatores operam na máquina pública brasileira, embora seja útil para
muitos fins, não é estritamente necessário para pensar estratégias mais gerais de mitigação de seus efeitos
(SUNDFELD; MARQUES NETO, 2013, p. 277-285). Comentando a Lei 13.655/2018, Marques Neto (2019, p. 13) lembra que:

Atento a esses fatores, já a algum tempo, um dos autores do presente livro (Floriano de Azevedo Marques Neto) juntamente com Carlos Ari Sundfeld redigiu um anteprojeto de lei, endereçando soluções para essas questões. O Senador Anastasia encampou essa iniciativa (...).

Em outras palavras, a partir de um diagnóstico pessoal do ambiente de aplicação do direito, ${ }^{4}$ naturalmente subjetivo e limitado, procedeu-se à uma grave alteração do sistema jurídico.

Com efeito, o ambiente de aplicação do Direito é muito mais complexo do que o sistema jurídico; o número de interações e possibilidades comunicativas é infindável e imprevisível,

\footnotetext{
${ }^{4}$ Cuida-se do diagnóstico referido no item 1 desse artigo.
} 
sendo, à toda evidência, não recomendável o doxismo, consistente em justificar-se um esboço de lei a partir da "experiência prática" de seus elaboradores. Cuidando dessa necessária distinção, ensina Luhman (2016, p. 208):

\begin{abstract}
As análises seguintes da diferença entre sistema e ambiente partirão da suposição de que o ambiente sempre é muito mais complexo do que o próprio sistema. Esse é o caso de todos os sistemas que podemos imaginar. Vale lembrar para o sistema social total da sociedade. Para ver isso logo de início, precisa-se apenas lembrar que a sociedade se constitui simplesmente de comunicações e que os dispositivos supercomplexos de macromoléculas individuais, de células individuais, de sistemas nervosos individuais e de sistemas psíquicos individuais pertencem ao seu ambiente - com todas as interdependências que existem entre esses sistemas, seja no mesmo nível ou em diferentes níveis.
\end{abstract}

Por mais complexo que seja o sistema jurídico, não é possível a previsão da integralidade das intercorrências no ambiente social e das soluções jurídicas para esses problemas produzidos pela sociedade. A sociedade brasileira - como qualquer sociedade - é muito complexa para ser regrada em todos os seus aspectos pelo legislador. Como lembra Luhman (2016, p. 208):

Seja quão complexo forem suas possibilidades linguísticas e quão sutil sua estrutura temática, a sociedade nunca pode possibilitar a comunicação sobre tudo o que se passa em seu ambiente em todos esses níveis de formação sistêmica em todos os sistemas. Por isso, como todo sistema, ela tem de estar em condições de compensar sua complexidade inferior própria mediante uma ordem superior.

Portanto, ter a pretensão de controlar as pessoas, as mentes dos agentes públicos que realizam as atividades de controle na realidade social, com base em uma lei de interpretação do Direito Administrativo brasileiro, é tarefa não só hercúlea como impossível. A Lei 13.655/2018 não tem o poder - aliás, como qualquer conjunto de normas jurídicas - de interferir de modo absoluto no ambiente de sua aplicação, com o qual, como sabido, não se confunde. O Estado no Brasil não é inimigo da sociedade brasileira, seja no plano normativo, do sistema jurídico como tal, seja na perspectiva pragmática, pois o Estado brasileiro tem interferido na realidade social permitindo avanços civilizatórios efetivos nas mais diversas áreas, como as de educação, saúde, transporte, previdência social, assistência social, saneamento etc., embora ainda se esteja longe do ideal.

A confusão entre Estado legal e Estado real é o segundo equívoco da justificativa do Projeto de Lei do Senado 349/2015 e, consequentemente, da Lei que alterou a LINDB (BERTONCINI, 2019, posição 3041-3075).

\title{
4. "Realidade total"
}


Há, ainda, um terceiro desacerto na justificativa do Projeto de Lei do Senado 349/2015: ao tratar da "realidade" não cuidou do real, ao partir do pressuposto de que o Estado sempre atua mal - "inimigo, jamais um parceiro" - e o particular é sempre vítima, seja esse particular pessoa física ou pessoa jurídica (empresa privada ou entidade da sociedade civil). Também é um exagero afirmar-se que o "aumento de regras sobre processos e controle da administração tem provocado aumento da incerteza e da imprevisibilidade e esse efeito deletério pode colocar em risco os ganhos de estabilidade institucional" (ANASTASIA, 2015, p. 49). Em outras palavras, o diagnóstico é impreciso do ponto de vista fático; como afirmado anteriormente, trata-se de uma doxa, de opinião pessoal transformada em verdade absoluta.

O sistema jurídico instituidor do Estado no Brasil não pode ser chamado de inimigo, tampouco acusado de colocar em risco os ganhos de estabilidade institucional. Esse sistema, para além de definir a República e a Democracia no plano constitucional, também concebe largo rol de direitos fundamentais aos brasileiros e estrangeiros residentes no País. O controle de legalidade existe para gerar certeza na aplicação do direito e não para produzir riscos e instabilidade; naturalmente, entretanto, o efetivo exercício do controle dos atos da Administração Pública pelos órgãos competentes pode produzir mudanças nos negócios jurídicos, total ou parcial, via invalidação ou retificação do ato. Nenhum ato é dotado de presunção absoluta de legalidade. Nessa medida, o risco e a instabilidade são inerentes a qualquer sistema de controle, não apenas ao sistema brasileiro de controle de legalidade.

Aliás, o vetado artigo 25 da LINDB $^{5}$ tentou essa proeza, mediante a criação de uma modalidade de ação civil pública declaratória de legalidade dos atos da Administração Pública, com efeito erga omnes, mediante a qual se permitiria que contratos e atos administrativos viciados, cujos defeitos ainda estivessem ocultos, pudessem ser blindados de futuras investigações pelos órgãos de controle. Em outros termos, proferida a sentença o Ministério Público, o Tribunal de Contas ou o próprio cidadão ficariam impedidos de pleitear a nulidade de negociatas, bem assim de buscar a punição dos autores de crimes ou atos de improbidade

\footnotetext{
${ }^{5}$ Art. 25. Quando necessário por razões de segurança jurídica de interesse geral, o ente poderá propor ação declaratória de validade de ato, contrato, ajuste, processo ou norma administrativa, cuja sentença fará coisa julgada com eficácia erga omnes.

$\S 1^{\circ} \mathrm{A}$ ação de que trata o caput será processada conforme o rito aplicável à ação civil pública.

$\S 2^{\circ} \mathrm{O}$ Ministério Público será citado para a ação, podendo abster-se, contestar ou aderir ao pedido.

$\S 3^{\circ}$ A declaração de validade poderá abranger a adequação e a economicidade dos preços ou valores previstos no ato, contrato ou ajuste.
} 
revelados somente após a prolação da decisão judicial. Essa proposição legislativa, como cediço, é fruto do diagnóstico já referido.

Presunções absolutas inexistem. Opor-se a isso é contrariar a natureza das coisas, é contrariar o próprio Estado de Direito. Não há segurança jurídica absoluta, assim como inexiste presunção de legalidade absoluta. De outra parte, o afastamento do controle de legalidade e, portanto, a ratificação dos atos da Administração Pública independentemente da existência de vícios trará um problema ainda maior: a convalidação de defeitos altamente lesivos à sociedade afetando sobremaneira o interesse público, o interesse da sociedade, em benefício de poucos privilegiados. Um contrato milionário superfaturado de obra pública é um bom exemplo. Quem ganha com a supressão do sistema de controle? É adequado afastar-se o risco dos envolvidos e conceder-lhes estabilidade diante desse quadro? A resposta, evidentemente, é negativa, embora o projeto contivesse o vetado artigo 25, que chegou a ser aprovado no Congresso Nacional.

Os fatores apontados na justificativa do Projeto de Lei do Senado 349/2015, que demandariam uma pesquisa de campo não realizada, expressam uma simplificação totalizante: “o alto grau de indeterminação de grande parte das normas públicas; a relativa incerteza, inerente ao Direito, quanto ao verdadeiro conteúdo de cada norma; a tendência à superficialidade na formação do juízo sobre complexas questões jurídico-públicas; a dificuldade de o Poder Público obter cumprimento voluntário e rápido de obrigação por terceiros, contribuindo para a inefetividade das políticas públicas; a instabilidade dos atos jurídicos públicos, pelo risco potencial de invalidação posterior, nas várias instâncias de controle; os efeitos negativos indiretos da exigência de que as decisões e controles venham de processos que demoram, custam e podem postergar cumprimento de obrigações; e o modo autoritário como, na quase totalidade dos casos, são concebidas e editadas normas pela Administração Pública”.

Trata-se o imaginário diagnóstico de verdadeira tautologia, expresso através de fórmulas muito genéricas: "alto grau de indeterminação", "relativa incerteza", "tendência à superficialidade", "dificuldade de obter cumprimento voluntário e rápido", "instabilidade dos atos jurídicos públicos" etc. A leitura da justificativa do projeto dá a impressão aos menos avisados de que se convive no Brasil com um Estado bandido, num ambiente absolutamente descontrolada. Como se afirmou anteriormente, o Estado no Brasil, no plano fático, não é ideal; no entanto, está distante do obscuro quadro pintado pelos articuladores do projeto. 
Ignorando a realidade brasileira, imersa numa grave crise ética, nota-se que o problema não está propriamente no Estado, mas numa parcela dos agentes do Estado e de particulares protagonistas de rumorosos escândalos de corrupção, em todos os níveis governamentais. A questão só não é pior, exatamente porque os órgãos de controle, especialmente os de controle externo, têm respondido - embora ainda não suficientemente - aos numerosos e lesivos casos de corrupção, a recomendar maior presença e eficácia desses órgãos e não o contrário, como defendido no Projeto de Lei do Senado 349/2015, convolado em Lei (BERTONCINI, 2019, posição 3075-3108).

A propósito, em tempos de pandemia, as fraudes perpetradas nas licitações destinadas às compras de medicamentos e insumos em geral para o combate do COVID-19, envolvendo inclusive governadores de Estado, bem reafirmam a necessidade de controle no lugar da inadequada recomendação de saneamento desses negócios viciados, conforme as mudança implementadas na LINDB.

\section{O elemento ideológico por detrás da alteração legislativa}

A Lei 13.655/2018, fruto do Projeto de Lei do Senado 349/2015, não faz distinção entre negócios jurídicos legítimos ou ilegítimos, legais ou ilegais, viciados ou não, ímprobos ou probos. Em três de seus dispositivos - 21, 24 e 27, e em um quarto - o artigo 25, que foi vetado -, nota-se claramente que a Lei teve a intenção de sanear, total ou parcialmente, negócios defeituosos, em nome da eficiência e da segurança jurídica, afastando ou reduzindo o impacto, os efeitos da atuação dos órgãos de controle interno e externo.

Conforme o parágrafo único do artigo 21, “[A] decisão que, nas esferas administrativa, controladora ou judicial, decretar a invalidação de ato, contrato, ajuste, processo ou norma administrativa deverá indicar de modo expresso suas consequências jurídicas e administrativas", e, "quando for o caso, indicar as condições para que a regularização ocorra de modo proporcional e equânime e sem prejuízo aos interesses gerais, não se podendo impor aos sujeitos atingidos ônus ou perdas que, em função das peculiaridades do caso, sejam anormais ou excessivos". Em outros termos, os órgãos de controle têm o dever de patrocinar a regularização do ato administrativo (em sentido amplo) inválido, preservando os efeitos econômicos do ato controlado, em proveito dos "sujeitos atingidos", que podem ser terceiros 
beneficiários do ato criminoso ou ímprobo. O "interesse geral”, que nesses casos não coincide com o interesse público primário, corresponde, ao menos em parte, ao interesse desses terceiros, conferindo a eles o direito ao produto do crime ou do ato de improbidade administrativa.

O artigo 24 estabelece que "[A] revisão, nas esferas administrativa, controladora ou judicial, quanto à validade de ato, contrato, ajuste, processo ou norma administrativa cuja produção já se houver completado levará em conta as orientações gerais da época, sendo vedado que, com base em mudança posterior de orientação geral, se declarem inválidas situações plenamente constituídas." Dito de outro modo, “situações plenamente constituídas”, embora posteriormente reconhecidas ilegais, defeituosas, viciadas, ímprobas ou até mesmo criminosas estão blindadas, não podendo ser controladas.

Ora, situações constituídas não podem impedir que a Administração Pública reconheça a ilegalidade de seu entendimento anterior e, por respeito à legalidade, à impessoalidade, à moralidade e à igualdade adote nova posição em sentido contrário. Situações já cristalizadas, imunes a mudanças de orientação, merecem ser assim consideradas caso a prescrição tenha atingido o direito de ação do Poder Público, que haverá de preservar os efeitos do ato jurídico produzido. Daí para se considerar qualquer mudança de posição incapaz de alterar o ato recentemente produzido com base em entendimento revisto, há uma perigosa e grande distância. A segurança jurídica não pode se sobrepor aos demais princípios da Administração Pública como um valor absoluto. A legalidade não pode ser afastada para se prestigiar negócios defeituosos consolidados, somente para se preservar, no plano pragmático, a "eficiência" e a “estabilidade institucional”.

Como leciona Emerson Gabardo (2016, p. 214):

A adoção de um sistema amplo de legalidade é um tiro no pé, pois em seu sentido amplo fraco, acaba por redundar em um sistema de princípios cuja aplicação ocorre pragmaticamente. Ou seja, o casuísmo tornase a regra e ainda que não se assuma tal postura, por certo que no fundo o que se busca é a eficiência da tomada de decisão por intermédio de interpretações subjetivas.

Já o artigo 27 estabelece: “[A] decisão do processo, nas esferas administrativa, controladora ou judicial, poderá impor compensação por benefícios indevidos ou prejuízos anormais ou injustos resultantes do processo ou da conduta dos envolvidos". Ora, no caso dos lucros serem indevidos e os prejuízos decorrerem da própria conduta dos envolvidos (crime, ato de improbidade administrativa, ato lesivo à Administração Pública etc.), não há o que se compensar. Além de corromper o sentido do que seja responsabilidade, o dispositivo corrompe 
o próprio sentido de Justiça, vitimando o autor do ilícito contra o interesse da coletividade e o protegendo da ação dos órgãos de controle. Novamente, e essa é uma questão importante, a indisponibilidade do interesse público foi substituída para se preservar os efeitos dos atos e contratos viciados da Administração Pública, inibindo o controle de legalidade, que, segundo a nova Lei, deve compensar os sujeitos autores de irregularidades indistintamente, pouco importando se autores ou beneficiários de atos de improbidade, crimes contra a Administração Pública etc.

A falta de harmonia entre essa Lei que alterou a LINDB e a Constituição parece evidente. Com efeito, o aludido diploma normativo faz tábula rasa dos princípios da legalidade, da moralidade e da impessoalidade para prestigiar negócios firmados com a Administração Pública, inclusive os impregnados de vícios produtores de responsabilidade civil, penal, administrativa ou por improbidade administrativa, violando princípios e regras do regime jurídico-administrativo (art. 37, caput) e as competências constitucionais do Ministério Público, do Tribunal de Contas, do Poder Judiciário e dos órgãos de controle interno da Administração Pública, em todos os níveis.

No que se refere ao Ministério Público, os mentores do projeto e o legislador desconsideraram que incumbe à essa instituição, com autonomia e independência, a "defesa da ordem jurídica, do regime democrático e dos interesses sociais e individuais indisponíveis" (artigo 127). Também cabe ao MP "promover o inquérito civil e a ação civil pública, para a proteção do patrimônio público e social, do meio ambiente e de outros interesses difusos e coletivos". Ora, se o patrimônio público é direito indisponível, como é que o legislador pode obrigar o Ministério Público a descumprir os princípios e regras constitucionais da Administração Pública e determinar que o órgão não atue contra os autores de crimes contra a Administração Pública, de atos de improbidade administrativa, de atos lesivos à Administração Pública etc., cobrando-lhes responsabilidades, inclusive no plano pecuniário. Diante da indisponibilidade do patrimônio público, o ressarcimento do dano deve ser integral, assim como integral também deve ser a perda dos bens decorrentes do enriquecimento ilícito.

As aludidas funções constitucionais são incompatíveis com a Lei 13.655/2018, a qual determina que, diante da declaração de nulidade de ato administrativo viciado, não se possa "impor aos sujeitos atingidos ônus ou perdas que, em função das peculiaridades do caso, sejam anormais ou excessivos" (artigo 21, parágrafo único); ou que situações constituídas são imunes 
à declaração de invalidade (artigo 24); ou, ainda, que se deva compensar por "benefícios indevidos ou prejuízos anormais ou injustos resultantes do processo ou da conduta dos envolvidos", onerando-se o Estado e desonerando-se o responsável pela ilegalidade (artigo 27).

Não é diferente com o Tribunal de Contas. A Lei 13.655/2018 simplesmente ignorou os princípios constitucionais que informam a atuação desse importante órgão de controle: legalidade, legitimidade e economicidade (MEDAUAR, 2014, p. 140-141). Com efeito, não podem as Cortes de Contas abrir mão de recursos públicos subtraídos, desviados ou mal empregados; diversamente, a CF atribui-lhes a competência de "aplicar aos responsáveis, em caso de ilegalidade de despesa ou irregularidade de contas, as sanções previstas em lei, que estabelecerá, entre outras cominações, multa proporcional ao dano causado ao erário" (artigo 70, inciso VIII). É, portanto, totalmente descabido pensar-se que o Tribunal de Contas da União ou os Tribunais de Contas dos Estados terão, a partir do advento da excêntrica Lei, que se omitir e não cobrar dos autores de prejuízos ao patrimônio público, ou, ainda pior, ter que autorizar a indenização dessas pessoas.

Quanto ao controle judicial, a pretensão do legislador quebra com a regra da autonomia e independência dos Poderes (artigo $2^{\circ}, C F$ ), impondo aos juízes e tribunais brasileiros obrigações que não lhes dizem respeito, como a que determina que "na interpretação de normas sobre gestão pública, serão considerados os obstáculos e as dificuldades reais do gestor e as exigências das políticas públicas a seu cargo" (artigo 22), vinculando o Judiciário aos motivos do administrador, sejam eles legítimos ou não, o que afeta a atribuição do Poder Judiciário de guarda da Constituição e das leis do País, em benefício da "segurança" e da "eficiência" econômica dos negócios firmados pela Administração Pública.

O mesmo se pode afirmar em relação ao controle parlamentar, inerente ao Poder Legislativo (BERTONCINI; SANCHES, 2011, p. 197-198), também impactado pela LINDB, com as alterações da Lei 13.655/2018. Aliás, é inacreditável que os legisladores não tenham detectado os diversos problemas do projeto, inclusive em detrimento de suas próprias funções de controle.

Reduzir ou aplacar o controle interno e externo da Administração Pública - como pretende a Lei -, além de não ser a solução pragmaticamente adequada em um País reconhecidamente marcado pelo problema da corrupção, constitui paliativo construído de 
forma descuidada, baseada em um diagnóstico frágil, sobre princípios mal orquestrados com os princípios constitucionais que integram o Direito Administrativo brasileiro, igualmente contrariando o trato constitucional atribuído às agências de controle - especialmente externas - da Administração Pública brasileira. No Brasil, o Estado não é exatamente o inimigo; o problema nacional são os inimigos do Estado, protagonistas dos escândalos de corrupção que infelizmente atingem a todos os brasileiros, especialmente os mais pobres.

Os três artigos mencionados - 21, 24 e 27 -, para dizer o menos, relativizaram o conhecido princípio do Direito Romano "nemo auditur propriam turpitudinem allegans" (ninguém pode se beneficiar da própria torpeza), e, por indução, parece que os mentores dessas regras criaram um novo princípio a informar as ações da Administração Pública: o princípio da prevalência do interesse privado sobre o interesse público, em provável colisão com os princípios do artigo 37, caput, da CF, e com as normas principiológicas que integram o regime jurídico-administrativo.

Parece evidente que foi a ideologia neoliberal a fonte inspiradora do Projeto de Lei do Senado e, consequentemente, da Lei 13.655/2018, que alterou a Lei de Introdução às Normas do Direito Brasileiro. Por esse viés ideológico, o Estado Social e Democrático de Direito, defensor dos interesses coletivos e prestador de serviços públicos destinados à concretização de direitos fundamentais (HACHEM, 2015, p. 80), ${ }^{6}$ não passa de um modelo de Estado ultrapassado.

$\mathrm{Na}$ linha das alterações implementadas na LINDB, presta-se o Estado a ofertar segurança aos particulares e eficiência aos contratos firmados por esses com a Administração Pública. Esse Estado mínimo, transformado em balcão de negócios, protege os interesses privados em detrimento dos interesses públicos. Nessa ambiência não há espaço para o desenvolvimento e a implementação da fraternidade (VERONESE; OLIVEIRA, 2013) e muito menos para a proteção e materialização de direitos fundamentais, concretizados a partir da prestação de serviços públicos pelo Estado.

A reforma implementada pela Lei 13.655/2018, alterando a Lei de Introdução às Normas do Direito Brasileiro, tem clara inspiração neoliberal, ideologia que está na base da globalização

\footnotetext{
${ }^{6}$ Segundo Daniel Wunder Hachem: “o serviço público se revela como o principal mecanismo de que dispõe a Administração para a realização de direitos fundamentais sociais".
} 
econômica (CHESNAIS, 1996), que tem por foco o mercado, a realização de negócios, a elevação de lucros, a preservação de ganhos a qualquer preço, mesmo quando em detrimento do interesse coletivo, do interesse público, expressão essa, aliás, não empregada no projeto e na Lei que reformou a LINDB (BERTONCINI, 2019, posição 3108-3209).

\begin{abstract}
A propósito, Celso Antônio Bandeira de Mello (2015, p. 1108-1109) assevera que:
O neocolonialismo encontra ambiente muito propício para medrar em nosso meio cultural e, pois, no seio do Direito Administrativo brasileiro, por termos, ainda, uma mentalidade acentuadamente marcada pela subserviência ideológica, típica do subdesenvolvimento de país que persiste pagando um pesado tributo ao colonialismo.
\end{abstract}

Eis aí a Lei 13.655/2018, para confirmar a lição mestre.

\title{
Conclusão
}

Respondendo à questão central da pesquisa, nota-se que o somatório dos elementos analisados anteriormente induzem à conclusão de que a pretensão do legislador com as alterações promovidas pela Lei 13.655/2018 na Lei de Introdução às Normas do Direito Brasileiro foi a de alterar as bases do Direito Público brasileiro, e, por conseguinte, do Direito Administrativo, para inocular no sistema jurídico nacional o implícito princípio da prevalência do interesse privado sobre o interesse público, em nome da eficiência e segurança dos negócios.

A compatibilidade dessa aparente mudança, inclusive em face da Constituição Brasileira, é assunto para outra pesquisa haja vista os limites próprios desse tipo de estudo.

\section{Referências}

ANASTASIA, Antonio. Apresentação, p. 5-7. In: SEGURANÇA JURÍDICA E QUALIDADE DAS DECISÕES PÚBLICAS: desafios de uma sociedade democrática. Coordenação: Flávio Henrique Unes Pereira. Brasília: Senador Federal, 2015. Disponível em: <http://antonioaugustoanastasia.com.br/wp-content/uploads/2015/09/segurancajuridica.pdf>. Acesso em: 09.07.2018.

- Justificativa, p 46-51. In: SEGURANÇA JURÍDICA E QUALIDADE DAS DECISÕES PÚBLICAS: desafios de uma sociedade democrática. Coordenação: Flávio Henrique Unes Pereira. Brasília: Senador Federal, 2015. Disponível em: 
<http://antonioaugustoanastasia.com.br/wp-content/uploads/2015/09/segurancajuridica.pdf > Acesso em: 09.07.2018.

BERTONCINI, Mateus. Princípios de Direito Administrativo Brasileiro, São Paulo: Malheiros Editores, 2002.

Aspectos ideológicos da nova Lei de Introdução às Normas do Direito Brasileiro e sua (in)compatibilidade com as categorias "fraternidade e serviço público". In: Direito e Fraternidade sob a Perspectiva da Construção Acadêmica: 10 Lições para os 10 Anos de Estudo da Fraternidade. Organizadoras: OLIVEIRA, Olga Maria Boschi Aguiar de; ROSSETTO, Geralda Magella de Faria. Florianópolis: Editora Deviante, 2019. Edição Kindle. Posição 2918-3283.

; SANCHES, Isabela Pinheiro. Controle Parlamentar sobre a Administração Pública, p. 188219. In: Revista Jurídica - UNICURITIBA, v,26, nº 10, 2011, Revista Eletrônica.

BOBBIO, Nortberto. Estado, Governo e Sociedade. Fragmentos de um dicionário político; tradução Marcos Aurélio Nogueira; posfácio Celso Lafer, 20ed. revista e atualizada. Rio de Janeiro/São Paulo: Paz e Terra, 2017.

CANOTILHO, José Joaquim Gomes. Direito Constitucional, 6ed. Coimbra: Livraria Almedina, 1993.

CHESNAIS, François. A Mundialização do Capital; tradução Silvana Finzi Foá. São Paulo: Xamã, 1996.

DI PIETRO, Maria Sylvia Zanella. Parcerias na Administração Pública, 11ed. Rio de Janeiro: Forense, 2017.

GABARDO, Emerson. A flexibilização da legalidade mediante o prestígio de uma ideia equivocada de eficiência e uma visão niilista da separação dos poderes, p. 2017-215. In: Direito Administrativo e suas transformações atuais - Homenagem ao professor Romeu Felipe Bacellar Filho: Anais do Seminário da Faculdade de Direito da Universidade Federal do Paraná. Coordenação: Daniel Wunder Hachem, Emerson Gabardo, Eneida Desiree Salgado. Curitiba: Íthala, 2016.

HACHEM, Daniel Wunder. Direito fundamental ao serviço público adequado e capacidade econômica do cidadão, p. 75-108. In: Eficiência e Ética na Administração Pública: Anais do 
Seminário Internacional realizado no Programa de Pós-Graduação em Direito da Pontifícia Universidade Católica do Paraná. Coordenação: Luiz Alberto Blanchet, Daniel Wunder Hachem, Ana Claudia Santano. Curitiba: Íthalo, 2015.

LUHMANN, Niklas. Sistemas Sociais: Esboço de uma Teoria Geral; tradução de Antonio C. Luz Costa, Roberto Dutra Torres Junior, Marco Antonio dos Santos Casanova. Petrópolis/RJ: Editora Vozes, 2016.

MARQUES NETO, Floriano de Azevedo; FREITAS, Rafael Verás de. Comentários à Lei no 13.655/2018 (Lei de Segurança para a Inovação Pública). Belo Horizonte: Editora Fórum, 2019. MARTINS JUNIOR, Wallace Paiva. Controle da Administração Pública pelo Ministério Público (Ministério Público Defensor do Povo). São Paulo: Editora Juarez de Oliveira, 2002. MEDAUAR, Odete. Controle da Administração Pública, 3ed. São Paulo: Revista dos Tribunais, 2014.

MELlO, Celso Antônio Bandeira de. Curso de Direito Administrativo, 32ed. São Paulo: Malheiros Editores, 2015.

MORAES, Alexandre. Direito Constitucional Administrativo. São Paulo: Editora Atlas, 2002.

SUNDFELD, Carlos Ari; MARQUES NETO, Floriano de Azevedo. Uma nova lei para aumentar a qualidade jurídica das decisões públicas e seu controle. In: Contratações Públicas e seu Controle. Organizador: Carlos Ari Sundfeld. São Paulo: Malheiros Editores, 2013, p. 277-285)

VERONESE, Josiane Rose Petry; OLIVEIRA, Olga Maria Boschi Aguiar de, organizadoras. Direito e Fraternidade. Rio de Janeiro: Lumen Juris, 2013. 